\title{
Rekürren omuz çıkığı tedavisinde Bankart tamiri ve klinik sonuçları
}

\author{
Bankart repair and clinical results in the treatment of \\ recurrent shoulder dislocation
}

\author{
Cem Nuri Aktekin ${ }^{1}$, Zafer Güneş² \\ ${ }^{1}$ Ankara Yıldırım Beyazıt Üniversitesi Tıp Fakültesi, Ortopedi ve Travmatoloji Ana Bilim Dalı, Ankara \\ ${ }^{2}$ Ankara Eğitim ve Araştırma Hastanesi, Ortopedi ve Travmatoloji Kliniği, Ankara
}

\begin{abstract}
Omuz eklemi geniş hareket açıklığına sahip olması ve kemik stabilizatörlerin görece azlığı nedeniyle vücutta en sık çıkığı ile karşılaşılan eklemdir. En yaygın patern ise omuz ekleminin antero-inferior çıkığıdır ve tüm çıkıkların yaklaşık \%90'ını oluşturmaktadır. Glenohumeral eklemin tekrarlayan anterior instabilitesi genellikle inferior glenohumeral ligamanın tutunma yeri olan anterior-inferior labrumun avülsiyonu nedeniyle oluşmaktadır ve Bankart lezyonu olarak bilinmektedir. Tekrarlayan çıkıklar ile antero-inferior labrum kompleksinde progresif hasar oluşmakta ve zamanla glenoid morfolojisi bozulmaktadır. Günümüzde geniş Hill-Sachs defekti ya da kritik glenoid kemik kaybı olmayan hastalarda en sık kullanılan cerrahi tedavi yöntemi artroskopik Bankart tamiridir. Ancak geniş Hill-Sachs ya da kritik glenoid kemik kaybı olan hastalarda korakoid transferi ya da remplisaj gibi ek kemik veya yumuşak doku prosedürleri gerekli olabilmektedir.
\end{abstract}

Anahtar sözcükler: Bankart; omuz; glenoid; dislokasyon
The shoulder joint is the most frequently dislocated joint in the body, due to its wide range of motion and the relative scarcity of bone stabilizers. The most common pattern is antero-inferior dislocation of the shoulder joint, accounting for approximately $90 \%$ of all dislocations. Recurrent anterior instability of the glenohumeral joint is usually caused by avulsion of the anterior inferior labrum, the attachment site of the inferior glenohumeral ligament, and is known as a Bankart lesion. With recurrent dislocations, progressive damage occurs in the antero-inferior labrum complex and the glenoid morphology deteriorates over time. Today, arthroscopic Bankart repair is the most commonly used surgical treatment method in patients without large Hill-Sachs defect or critical glenoid bone loss. However, patients with extensive Hill-Sachs or critical glenoid bone loss may require additional bone or soft tissue procedures, such as coracoid transfer or remplissage.

Key words: Bankart; shoulder; glenoid; dislocation
O muz eklemi geniş hareket açıklığına sahip olması ve kemik stabilizatörlerin görece azlığı nedeniyle vücutta en sık çıkığı ile karşılaşılan eklemdir. ${ }^{[1-3]}$ En yaygın tipi (paterni) ise omuz ekleminin antero-inferior çıkığıdır ve tüm çıkıkların yaklaşık \%90'ını oluşturmaktadır. Genel popülasyonda travmatik anterior glenohumeral instabilite insidansı $\% 1,7^{\prime}$ dir. ${ }^{[4]}$ ilk çıkık sonrası tekrarlayan çıkık sıklıkla görülmektedir ve genç yaş ile yüksek aktivite seviyesi en önemli risk faktörleridir. ${ }^{[5,6]}$ Hovelius ve ark. 25 yıllık izlem içeren 229 hastadan oluşan çalışmalarında 30 yaş üstü hastalarda tekrarlayan (rekürren) çıkık \%27 olarak raporlanmışken, 22 yaş altı hastalarda bu oran \%72 olarak belirtilmiştir. ${ }^{[6]}$ Glenohumeral ekle- min tekrarlayan anterior instabilitesi genellikle inferior glenohumeral ligamanın tutunma yeri olan anterior inferior labrumun avülsiyonu nedeniyle oluşmaktadır ve Bankart lezyonu olarak bilinmektedir. Tekrarlayan çıkıklar ile antero-inferior labrum kompleksinde ilerleyici (progresif) hasar oluşmakta ve zamanla glenoid morfolojisi bozulmaktadır. Greis ve ark. yapmış oldukları çalışmada glenoid antero-inferiorunda oluşan labral hasar ve kemik defekti sonrası glenohumeral eklem basıncının \%300'e kadar artabildiği gösterilmiştir. ${ }^{[7]}$ 1923'te Bankart, tekrarlayan anterior instabilitenin birincil nedeni olduğuna inandığı lezyonu tanımlamıştır. ${ }^{[1]}$ Bankart tarafından lezyon tanımlanana kadar tekrarlayan anterior omuz instabiliteleri atletler ve epilep-

İletişim / Contact: Prof. Dr. Cem Nuri Aktekin • E-posta / E-mail: cemnuri@yahoo.com

ORCID iD: Cem Nuri Aktekin, 0000-0001-5240-8516 • Zafer Güneş, 0000-0001-7501-0180

Geliş / Received: 22 Ocak 2021 • Kabul / Accepted: 15 Şubat 2022 
tik hastalar ile ilişkili bir fenomen olarak kabul edilirken, Bankart omuz eklem kapsülünün doğal olarak gergin bir yapı olmadığını belirtmiş ve tekrarlayan omuz instabilitesinin nedeni olarak ise kapsüloligamentöz bileşkenin glenoid anteroinferior yarısından ayrılması olarak tanımlamıştır. Bankart, dönemin cerrahlarının yaptıkları ameliyat ile herhangi bir eklem stabilitesi elde etmediklerini, omuz kapsülünün aşırı gerilmesi sonucu sadece omuz eklem hareketlerinin aşırı kısıtlandığını düşünmekteydi. Uzun yıllar boyunca Bankart lezyonunun tedavisinde açık teknikler altın standart olarak kabul edilmiştir. ${ }^{[8,9]}$ Ancak 1990'lı yıllarda ilk artroskopik Bankart onarımının tanımlanması ve zamanla popüler olması sonrası günümüzde gelişen cerrahi aletler ve cerrahların artan tecrübesi ile artroskopik teknik cerrahi tedavide en sık kullanılan yöntem olmuştur. ${ }^{[10,11]}$

\section{ENDIKASYONLAR}

Artroskopik Bankart onarımı için en önemli endikasyon belirgin oranda glenoid kemik kaybı olmayan Bankart lezyonlarıdır. Balg ve ark. ameliyat sonrası rekürrens riskini değerlendirmek üzere instabilite şiddeti indeks skorunu (işis) önermişlerdir (Tablo 1). ${ }^{[13]} \mathrm{Bu}$ skorlama sistemine göre 7 veya daha yüksek skora sahip hastalarda cerrahi sonrası rekürrens riski \%70 iken, 6 veya daha az skora sahip hastalarda ise rekürrens riski sadece \%10'dur. ${ }^{[13]}$ Phadnis ve ark.'nın yapmış oldukları çalışmada 141 hastanın 19'unda cerrahi sonrası tekrar çıkık görmüşlerdir ve çıkık görülen hastalarda ortalama işis 5,1 iken tekrar çıkık görülmeyen hastalarda ise bu skorun ortalama 1,7 olduğu görülmüştür. ${ }^{[14]} \mathrm{Her}$ ne kadar düşük fiziksel aktivite düzeyine sahip hastalarda ilk çıkık sonrası fizik tedavi uygun bir tedavi seçeneği olsa da fiziksel olarak aktif, genç hastalarda ameliyat dışı yöntemlerle tedavi edilmiş ilk çıkık sonrası tekrarlayan çıkık olasılığı \%90'lara kadar çıkabilmektedir. ${ }^{[15]}$ Yüksek tekrarlayan glenohumeral instabilite riskine sahip ya da cerrahi dışı yöntemlerle tedavi sonrası tekrarlayan instabilite öyküsü olan hastalarda artroskopik Bankart onarımı uygun bir

Tablo 1. Instabilite şiddeti indeks skoru (işis) ${ }^{[13]}$

\begin{tabular}{lc}
\hline Kriter & Puan \\
\hline$\leq 20$ yaş & 2 \\
Rekabetçi sporlara katılım & 2 \\
Eksternal rotasyonda AP grafide Hill-Sachs lezyonu & 2 \\
AP grafide glenoid kontür kaybı & 2 \\
Temas ya da başüstü sporlara katılım & 1 \\
Omuz ekleminde anterior ya da inferior laksite & 1
\end{tabular}

tedavi seçeneğidir. Ancak glenoid eklem yüzeyinin \%25 veya daha fazlası kadar kemik kaybı olan veya geniş, angaje Hill-Sachs lezyonu olan hastalarda sadece artroskopik Bankart onarımı uygun bir tedavi yöntemi değildir ve bu hastalarda sadece artroskopik Bankart onarımı yapılması kontraendikedir. ${ }^{[16]} \mathrm{Bu}$ nedenle açı/artroskopik glenoid kemik greftleme, remplisaj gibi ek prosedürler ya da artroskopik Bankart onarımı gibi tedavi seçenekleri arasında seçim yaparken hastanın yaşı, aktivite düzeyi, glenoid kemik kaybı ve hastanın beklentileri gibi kriterler dikkate alınmalı ve hastaya göre en uygun tedavi seçeneği uygulanmalıdır.

Omuz eklemi hareketi sırasında maksimum hareket sınırına gelene kadar eklem etrafında daire çizer. Bu dairenin oluşturduğu alana "mid-range" adı verilmektedir. Omuz eklem kapsülünün gerildiği ve humerus başının glenoid soketten translasyonunun önlendiği hareket sınırına ise "end-range" denilmektedir. Yani omuz eklem kapsülünün gevşek olduğu ve eklemin istediği yönde hareket edebildiği aşama "mid-range" olarak adlandırılmaktadır. Kol maksimum abduksiyon, eksternal rotasyon ve horizontal ekstansiyon yaparken, glenoid ile humeral başın posterior eklem yüzü sınırı arasındaki temas alanına "glenoid track" denilmektedir. Glenoid kemik kaybı olması durumunda bu temas alanı küçülmektedir. Eğer Hill-Sachs lezyonu bu glenoid track medialine uzanıyorsa off-track lezyon olarak, uzanmıyorsa "on-track" lezyon olarak adlandırılır. Off-track lezyonlarda humerus başının hareket sırasında glenoid kenarına angaje olması ve rekürren çıkığa sebep olması beklenmektedir. Glenoid kemik kaybı olması durumunda, Hill-Sachs lezyonunun glenoid anterioruna angaje olması için katetmesi gereken mesafe kısalmaktadır ve daha kolay tekrarlayan çıkık gelişebilmektedir. Hem glenoid antero-inferior kenarında hem de humerus başında kemik kaybı olan hastalarda izole Bankart tamiri yapılması ameliyatın başarı şansını düşürmektedir. Locher ve ark. Hill-Sachs lezyonu olan hastalarla yaptıkları çalışmada, off-track lezyonu olan hastalarda \%33 revizyon cerrahi gerekliliği görülürken on-track lezyonu olan hastalarda ise bu oran sadece $\% 6$ olarak bulunmuştur. ${ }^{[17]}$

\section{TEDAVi}

\section{Artroskopik Bankart Onarımı}

Artroskopik Bankart onarımı, açık Bankart onarımı ile karşılaştırıldığında daha küçük cilt insizyonu, daha kısa cerrahi süre, ameliyat sonrası daha az ağrı ve daha az ağı kesici kullanımı, daha az kan kaybı, daha az komplikasyon ve artmış eklem hareket açıklığı gibi avantajlara sahiptir. ${ }^{[12]}$ Sonuç olarak artroskopik Bankart onarımı eklem fonksiyonunun daha iyi korunması ve daha hızı 


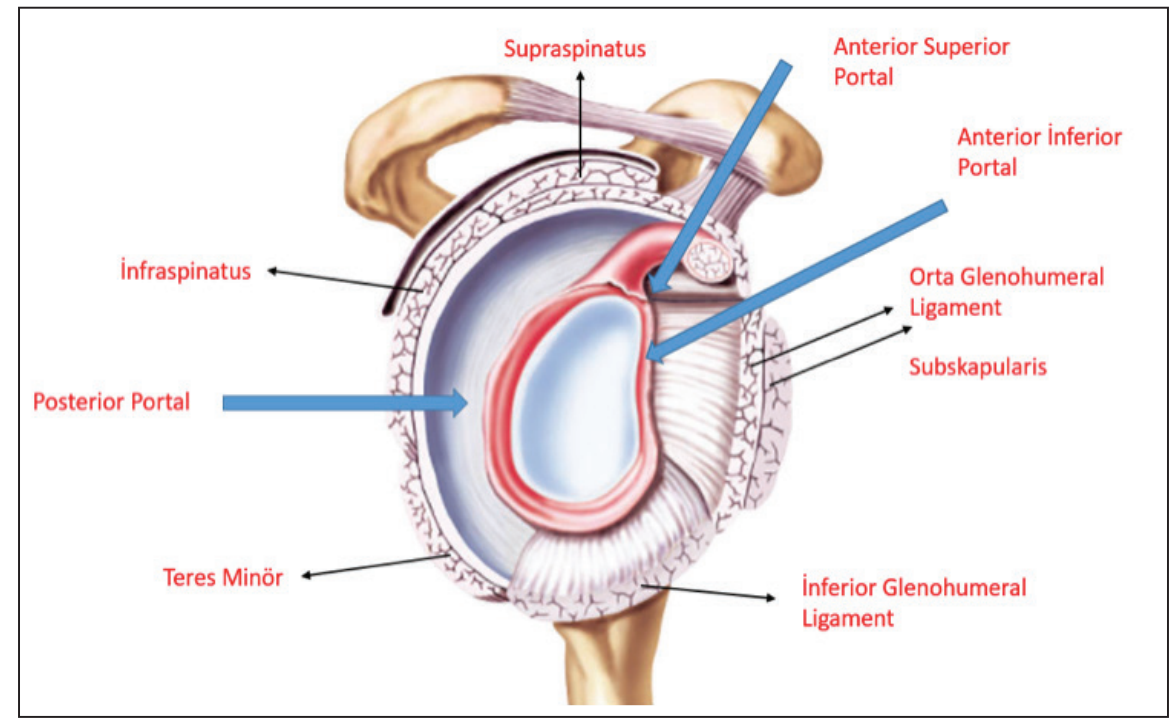

Şekil 1. Sağ omuz için; sagital düzlemde artroskopik portaller.

iyileşme, sportif faaliyetlere daha hızlı dönüş ve kozmetik açıdan açık Bankart onarımına göre daha üstündür. ${ }^{[12,18]}$

Artroskopik Bankart onarımı cerrahın tecrübesi ve tercihine göre standart olarak şezlong pozisyonda ya da lateral dekübit pozisyonda yapılmaktadır. Hasta pozisyonlaması sonrasında omuz eklemi etrafındaki akromion, korakoid çıkıntı (process), akromioklavikular eklem ve klavikula distali gibi anotomik belirteçler işaretlenir. Akromionun posterolateral köşesinin $2 \mathrm{~cm}$ distali ve $1 \mathrm{~cm}$ medialinden görüntüleme amacıyla kullanılmak üzere posterior portal açııı (Şekil 1). Artroskopiye tanısal artroskopi ile başlanır. Tanısal artroskopide humerus başı, biseps tendonu, labrum, kapsül, rotator manşet ve varsa Hill-Sachs lezyonu dikkatli bir şekilde değerlendirilir. Böylece hem Bankart lezyonu hem de ilişkili diğer patolojiler tespit edilmiş olur. Labrum ön kısmında yer alan lezyonlar açıkça görülebilirken, labral yırtığın arka veya üst uzantıları ince olabilir ve ancak artroskopi probu ile muayene sırasında anlaşılabilir. Kol abduksiyon ve dış rotasyona alınarak eklemin dinamik değerlendirmesi yapılır ve böylece Hill-Sachs lezyonunun angaje olup olmadığı anlaşılabilir. Glenoid, saat kadranı şeklinde değerlendirilir ve en alt köşesi saat 6 'ya işaret ederken en tepe noktası saat 12 olarak kabul edilir. Diagnostik artroskopiyi takiben bir iğne yardımıyla deltopektoral aralıktan anterior-inferior ve sonrasında anterior-superior portaller açılır (Şekil 1). Cerrahın tercihine göre tek veya çift anterior portal ile artroskopik Bankart onarımı yapılabilir.

Onarım için önce dikiş (suture first) ya da önce ankor (anchor first) tekniği kullanılır. Suture first tekniğinde labrum glenoid anteriordan kaldırılır ve yumuşak doku iyileşmesini arttırmak için artroskopik shaver ya da raspa ile glenoid anterior kenarına debridman ve dekortikasyon işlemi yapılır (Şekil 2). Bankart onarımının düzgün bir şekilde yapılabilmesi için bu aşamada kapsülolabral kompleksin yeterli mobilizasyonu sağlanmalıdır. Fiksasyon öncesi kapsülolabral kompleks anteriora doğru tamamen serbest olarak hareket edebilmelidir.

Bankart lezyonunun glenoid antero-inferior kenara fiksasyonu için pek çok yöntem vardır ancak bunlar içerisinde en sık kullanılanı dikiş çapalarıdır (Şekil 3). illk çapanın yeri uygun bir kapsüler kaydırma yapılabilmesi için çok önemlidir. İlk çapa sağ omuzda yaklaşık saat 5 hizasında ve frontal plana $45^{\circ}$ lik açı ile ve glenoid

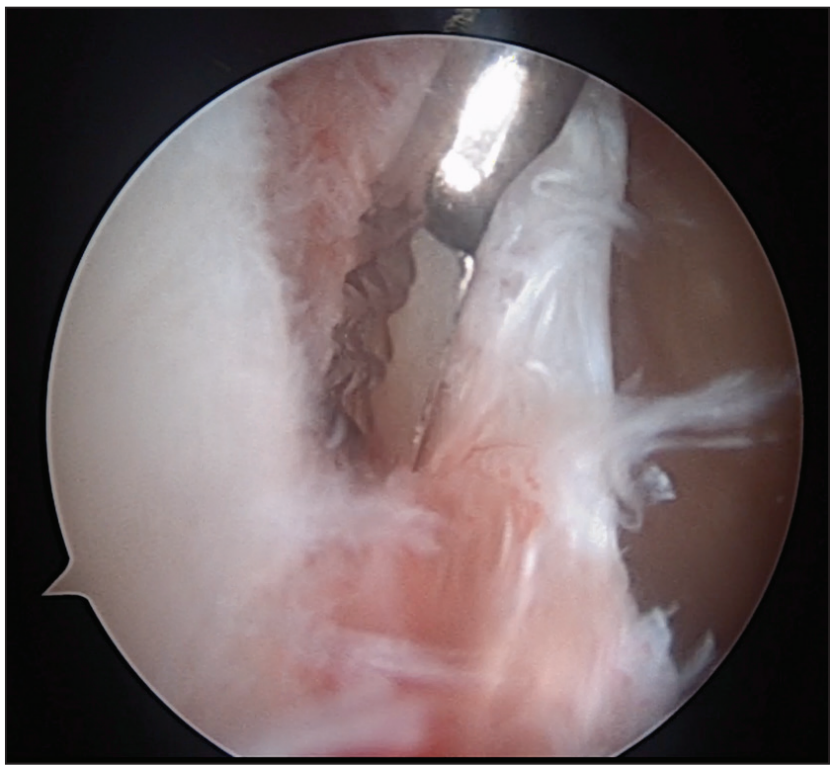

Şekil 2. Artroskopik debridman ve dekortikasyon ile glenoid anterior kenarının hazırlanması. 

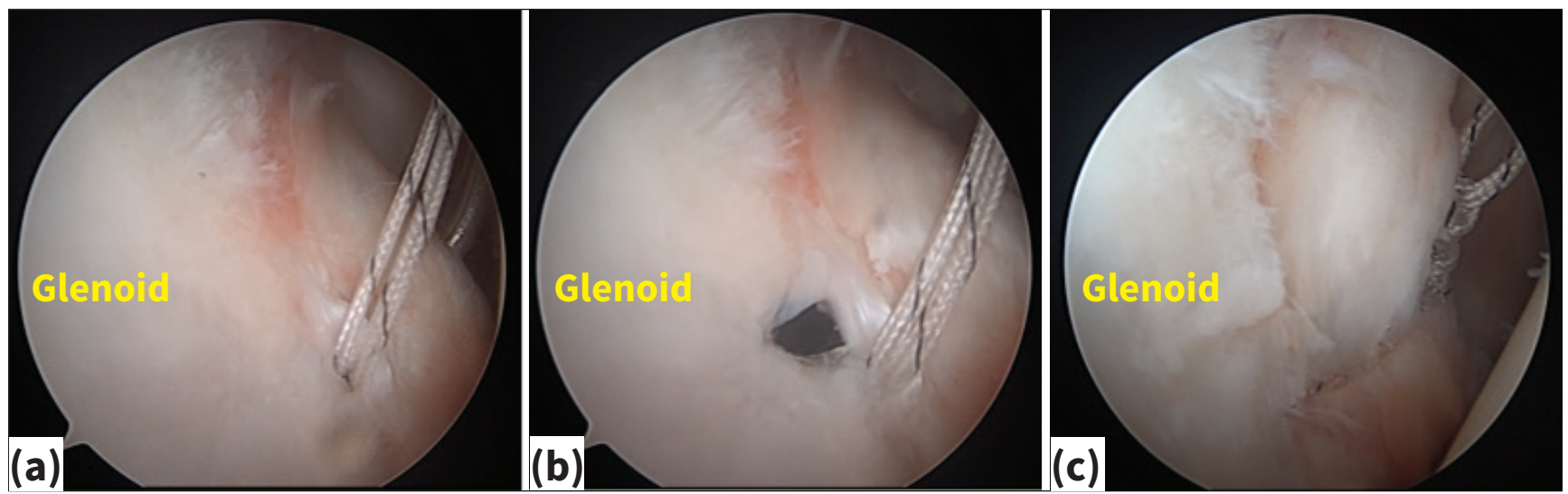

Şekil 3.a-c. Glenoidin hazırlanmasından sonra kapsüloligamentöz kompleksin glenoid anterior kenarına dikiş çapası ile tespiti (fiksasyonu).

kıkırdağın hemen yanına konulmalıdır. İnferior glenohumeral ligamenti de içerecek şekilde superior kaydırma yapılması önemlidir. Sütürun olabildiğince inferiordan yerleştirilmesi (tercihen saat 6 düzeyi) için çeşitli teknikler mevcuttur:

1. Artroskop antero-superior portale yerleştirilir ve sütür posterior portalden bir sütür geçirici ile labrumdan geçirilir.

2. Artroskop posterior portale yerleştirilir ve antero-inferior portalden bir sütür geçirici ile labrumdan geçirilir. İnferior kapsüle erişim zor ise traksiyon sütürü kullanılabilir. Traksiyon sütürü ile dokunun daha inferioruna erişim mümkün olabilmektedir.

Labrumdan sütürların geçirilmesinden sonra dikiş çapası yerleştirilir. Illk dikiş çapası glenoid üzerinde, ilk sütürün geçirildiği saat 6 seviyesinin $5-10 \mathrm{~mm}$ superioruna yani saat 5 seviyesine yerleştirilir. Böylece labrumun superior kaydırma işleminin yapılması amaçlanır. Dikiş çapası, normal labrumun tampon etkisini elde edebilmek için glenoid eklem yüzeyine konulur.

Anchor first tekniğinde ise yine aynı genel tekniklerle işleme başlanır. Glenoid eklem yüzü inferiorunda saat 5 pozisyonunda dikiş çapası yerleştirilir. Sütür yönetimi için dikiş çapasının ipleri kanülden çıkarııı. Labrumdan geçirilen sütürler eklem içine sıkı bir şekilde tutturulur.

Nho ve ark. yaptıkları çalışmada basit dikiş, horizantal matris dikiş ile dikiş çapası, basit dikişli çift yüklü dikiş çapası ve düğümsüz dikiş çapasını biyomekanik açıdan karşılaştırmışlardır. ${ }^{[19]}$ Bu çalışma sonuçlarına göre tekrarlayan $25 \mathrm{~N}$ yük altında tüm dikiş yöntemlerinde 2 mm'den daha az deplasman olduğu görülmüştür. ${ }^{[19]}$ Fakat yetmezlik için gereken maksimum yük açısından değerlendirildiğinde düğümsüz dikiş çapasında yetmezlik gelişmesi için daha az maksimum kuvvet gerektiği görülmüştür. ${ }^{[19]}$ Hagstrom ve ark. Bankart lezyonu oluş- turdukları 16 kadavra içeren çalışmalarında saat 3:30, 4:30 ve 5:30 pozisyonlarına toplam üç adet düğümlü sütür çapası yerleştirmiştir. Daha sonra kadavraların yarısında basit sütür tekniği ile ve diğer yarısında horizantal matris sütür tekniği ile Bankart lezyonu onarımı yapmışlardır. Basit sütür tekniği ile Bankart onarımı yapılan kadavralarda sağlam omuzlarına göre her üç pozisyonda da istatiksel anlamlı labral yükseklik kaybı tespit etmişlerdir. Horizantal matriks sütür tekniği uygulanan omuzlarda ise hiçbir pozisyonda anlamlı yükseklik kaybı tespit edilmemiştir. ${ }^{[20]}$ Dikiş çapası sayısı açısından değerlendirildiğinde ise; Shibata ve ark. yaptıkları çalışmada dörtten az çapa kullanımını yetmezlik açısından yüksek riskli bulunmuştur. ${ }^{[21]}$ Yine Boileau ve ark. yaptığı çalışmada üç veya daha az dikiş çapası kullanımını yetmezlik açısından yüksek risk ile ilişkilendirmişlerdir. ${ }^{[22]}$ Ancak bunun tersini söyleyen çalışmalar da mevcuttur. Brown ve ark. yaptıkları meta-analize göre toplam 14 çalışma dikiş çapası sayısı açısından karşılaştırılmıştır. Bu çalışmaya göre üçten az dikiş çapası kullanılan hastalarda tekrar çıkık oranı \%15 iken, üç veya daha fazla dikiş çapası kullanılan hastalarda ise bu oran \%11,4 olarak bulunmuştur ve anlamlı fark saptanmamıştır. ${ }^{[23]}$

\section{Artroskopik Kapsüler İmbrikasyon (Gerdirme)}

Termal kapsülorafi ilk olarak 1990'lı yıllarda pek çok cerrah tarafından kullanılmış ve popülarize edilmiştir. ${ }^{[24,25]} \mathrm{Bu}$ teknikte bir monopolar radyofrekans probu ile kapsül ısıtılarak ve kollajen molekülleri denatüre edilerek kapsül alanının azaltılması amaçlanmaktadır. Bugün için artroskopik stabilizasyon üzerinde belirgin bir fayda sağlamadığı gösterilmiş ve artık günümüzde terk edilmiştir. [26,27] 2005 yılında Sekiya, kapsülde bir kesi gerektirmeden kapsülün üst üste bindirilmesi ile hacminin azaltılması işlemi olan çok katlı kapsüler imbrikasyonu tanımlamıştır. ${ }^{[28]} \mathrm{Bu}$ yöntemde kapsüler hacim, dikiş çapasının 
bacakları kullanılarak kapsülün yakalanması ve üst üste birleştirilerek imbrikasyonu ile azaltılmaktadır. Sekiya ve ark. tarafından yapılan kadavra çalışmasında; kapsüler imbrikasyon ile açık kapsüler kaydırmaya göre kapsüler hacimde \%13 daha fazla azalma olduğu gösterilmiştir. ${ }^{[29]}$

\section{Bristow-Laterjet Prosedürü}

Glenoid anteriorunu güçlendirmek için korokoid çıkıntı transferi ilk olarak 1954 yılında Laterjet tarafından tanımlanmıştır. ${ }^{[30]}$ Glenoid kemik kaybı \%20-30 üzerinde olan hastalarda yüksek oranda rekürren instabilite bildirilmektedir. Ciddi glenoid kemik kaybı olan hastalarda bu teknik düşük oranda rekürren instabilite, sportif faaliyetlere yüksek oranda dönüş olması ve yüksek hasta tatmini sağlaması ile kapsülolabral onarıma alternatif bir tedavidir. ${ }^{[31]}$ Bu prosedürde korakoid tipi buraya yapışan biseps tendonu kısa başı ve korakobrakialis (conjoint tendon) ile beraber osteotomize edilir. Bu kemik blok subskapularis kası split geçilerek glenoid anterioruna bir adet vida ile fikse edilir. Bu işlemin iki önemli etkisi vardır: ${ }^{[16]}$

1. Bu kemik blok glenoidin ön çapını arttırır.

2. Korakoid tipine tutunan conjoint tendon dinamik bir askı görevi görerek kol abduksiyon ve dış rotasyondayken subskapularis kası inferiorunu aşağı çekerek inferior kapsülü güçlendirir.

$\mathrm{Bu}$ prosedür açık veya artroskopik olarak, glenoid kemik kaybı \%20-30 üzerinde olan primer vakalarda ya da revizyon vakalarında yaygın olarak kullanılmaktadır. Hovelius ve ark. yapmış oldukları 118 hasta ve 15 yıllık takip içeren prospektif çalışmada \%98 hasta tatmini ve \%3,4 tekrarlayan çıkık bildirmişlerdir. ${ }^{[32]}$

\section{Hill-Sachs Lezyonlarının Yönetimi}

Hill-Sachs lezyonu anterior glenohumeral çıkık sonrası humerus başının kompresyon kırığıdır. Geniş HillSachs defektleri humerus başının glenoid anterior kenara angaje olmasına ve dirençli instabiliteye yol açabilmektedir. Bankart onarımı, korakoid transferi veya kapsüler imbrikasyonun amacı humerus başının angaje olacağı mesafeyi arttırarak dirençli instabilliteyi engellemektir. Bu amaçla çeşitli cerrahi tedavi seçenekleri mevcuttur. Hill-Sachs defektinin humeral yada femoral baş allogreftleri ile rekonstrüksiyonu tedavi seçeneklerinden biridir. Miniaci ve ark. 18 hastayı içeren çalışmalarında defekti humeral baş allogrefti ile onarmışlar ve başarılı sonuç bildirmişlerdir. ${ }^{[33]}$ Günümüzde angaje Hill-Sachs defektlerinde en popüler tedavi yöntemi artroskopik remplisajdır. Burada amaç kemik defektinin posterior kapsül ile doldurulmasıdır. Longo ve ark.'nın yapmış olduğu ve 26 çalışmanın yer aldığı gözden geçirme çalışmasına göre humeral defektlerin cerrahi tedavisinde remplisaj en güvenli teknik olarak bulunmuştur. ${ }^{[34]}$ Yine bu çalışmada kombine remplisaj-Bankart prosedürü sadece Bankart prosedürüne göre daha az rekürrens oranına sahiptir. Artroskopik remplisaj prosedürü diğer tedavi yöntemlerine göre en güvenli, en düşük komplikasyona sahip ve en stabil tedavi seçeneği olarak belirtilmiştir.

\section{TARTIŞMA}

Endikasyonların genişlemesi, cerrahi teknik ve aletlerde yaşanan gelişmelerle anterior omuz stabilizasyon cerrahisi günümüzde oldukça yaygın uygulanan işlemlerdir. Bankart onarımı sonrası rekürrens oranı çeşitli yayınlarda \%4 ile 19 arasında bildirilmektedir ve temas, mücadele ve başüstü sporlarla uğraşan hastalarda risk diğer popülasyona göre daha yüksektir. ${ }^{[35]}$ Virk ve ark.'nın yaptığı 80 hasta içeren çalışmalarında açık Bankart onarımı yapılan hastalarda cerrahi sonrası ilk çıkığa kadar geçen süre 34,2 ay iken artroskopik Bankart onarımı yapılan hastalarda bu süre 12,6 ay olarak bulunmuştur. ${ }^{[36]}$

Dikiş çapasının yapısı, tasarımı, kullanılan dikiş çapası sayısı ve rotator intervalin kapatılmasının rekürren instabilite sonrası artroskopik Bankart onarımının başarısına ve stabilite üzerine etkileri hâlâ tartışmalıdır. Chechik ve ark.'nın yaptığı çalışmada artroskopik Bankart onarımı yapılan hastalarda rotator interval kapamanın stabilite ve fonksiyonel sonuçlar üzerine etkileri araştırılmıştır. Otuz yedi hastaya artroskopik Bankart onarımı ve rotator interval kapama işlemi yapılırken 46 hastaya sadece artroskopik Bankart onarımı uygulanmıştır. Tekrarlayan çıkık (re-dislokasyon) ve klinik sonuçlar açısından gruplar arasında anlamlı herhangi bir fark saptanmamıştır. ${ }^{[37]}$ Emilemeyen sütürlerle uzun süreli fiksasyon elde edilebilmekte ve bu da kemik-yumuşak doku ara yüzünde yeterli iyileşmenin olabilmesi için gerekli süreyi sağlamaktadır. Ancak günümüzde emilebilir dikiş çapaları da yaygın olarak kullanılmaktadır. Bu dikiş çapalarına bağı erken emilim, dikiş çapasının geri gelmesi, eklem içi debrisler, osteoliz ve kist formasyonu gibi komplikasyonlar bildirilmektedir. Milano ve ark. yaptığı çalışmada emilebilir dikiş çapası kullanılan hastalarda \%5,9 (2/34) tekrarlayan çıkık bildirilirken emilemez dikiş çapası kullanılan hastalarda ise bu oran \%2,8 (1/36)'dir. ${ }^{[38]}$ Tan ve ark.'nın yaptığı çalışmada ise emilebilir dikiş çapası kullanılan grupta tekrarlayan çıkık \%6,6 (4/61) iken emilemez dikiş çapası kullanılan hastalarda bu oran \%6,3 (4/63) olarak bildirilmiştir. ${ }^{[39]}$ Sonuç olarak emilebilir ve emilemez dikiş çapalarının klinik sonuçlar üzerinde etkileri açısından aralarında anlamlı bir fark saptanmamıştır.

Bankart tamiri sonrası genellikle ortalama eksternal rotasyon sağlam tarafa göre azalmaktadır. Pek çok 
çalışmaya göre artroskopik Bankart tamiri sonrası açık cerrahiye göre ameliyat sonrası eklem sertliği daha az görülmektedir. ${ }^{[40]}$ Wang ve ark.'nın yaptığı 11 çalışma içeren meta-analize göre; 512 hastaya artroskopik Bankart tamiri ve 510 hastaya açık Bankart prosedürü uygulanmıştır. Bu çalışma sonucuna göre artroskopik cerrahi sonrası eklem hareket açıklığının açık cerrahiye göre daha iyi olduğu görülmüş ancak açık cerrahi ile de daha stabil bir omuz elde edildiği görülmüştür. Yine bu çalışma sonucuna göre artroskopik Bankart onarımı yapılan grupta eksternal rotasyonun daha iyi olduğu görülmüştür. ${ }^{[41]}$ Geniş Hill-Sachs ve kritik glenoid kemik kaybı olması durumunda açık veya artroskopik Bankart onarımı yeterli olmamakta, Laterjet ya da remplisaj gibi ek prosedürlere gereksinim olmaktadır. Haroun ve ark.'nın yaptığı meta-analizde geniş Hill-Sachs'ı ve kritik glenoid kemik kaybı sebebiyle Laterjet prosedürü uygulanan 185 hasta ile artroskopik Bankart onarımı+remplisaj yapılan 194 hasta karşılaştırılmıştır. Gruplar arasında ameliyat sonrası ortalama Rowe skoru (omzu stabilite, hareket ve fonksiyon açısından değerlendirir), görsel ağrı skalası (VAS, Visual Analogue Scale) iç ve dış rotasyon dereceleri açısından fark saptanmamıştır. Laterjet yapılan hastalarda ameliyat sonrası tekrar çıkık oranı \%7 iken bu oran artroskopik Bankart tamiri ve remplisaj yapılan grupta $\% 9,8$ olarak saptanmıştır. ${ }^{[42]}$

Bankart tamiri sonrası güncel çalışma sonuçlarına göre hastaların \%80-90'ı spora tekrar dönebilirken, \%5060'ı yaralanma öncesi seviyeye ulaşabilmektedir. ${ }^{[15,43]}$ Aboalata ve ark.'nın yaptığı 119 artroskopik Bankart tamiri uygulanmış hasta içeren çalışma sonuçlarına göre ameliyat sonrası hastaların sadece $\% 49,5$ 'i yaralanma öncesi atletik düzeylerine ulaşabilirken $\% 30,25$ ' $\mathrm{i}$ ise atletik düzeylerinde azalma olduğunu belirtmişlerdir. Hastaların $\% 20,25$ 'i ise aynı spora tekrar dönememiştir. ${ }^{[15]}$ Memon ve ark.'nın yaptığı 34 çalışmanın yer aldığı meta-analize göre hastaların \%82'si spora geri dönmüştür ancak sadece \%66'sı yaralanma öncesi seviyeye ulaşabilmiştir. ${ }^{[44]}$

Sonuç olarak artroskopik Bankart onarımı; belirgin glenoid kemik kaybı ya da geniş Hill-Sachs lezyonu olmayan hastalarda günümüzde düşük komplikasyon oranları ve çok iyi fonksiyonel sonuçları ile en çok tercih edilen cerrahi tedavi yöntemidir. Doğru endikasyonla doğru hastada uygulandığında düşük rekürren instabilite ve yüksek işe ya da spora dönüş oranlarına sahiptir. Geniş Hill-Sachs defekti ya da glenoidde \%20-30'dan fazla kemik kaybı olduğu durumlarda tek başına Bankart onarımı yeterli olmamakta, mutlaka tedaviye remplisaj veya Laterjet gibi ek yumuşak doku veya kemik prosedürleri eklenmelidir.

\section{KAYNAKLAR}

1. Bankart A.S. Recurrent or habitual dislocation of the shoulder joint. Br Med J 1923;2(3285):1132-3. Crossref

2. Bigliani LU, Kelkar R, Flatow EL, Pollock RG, Mow RG. Glenohumeral stability. Biomechanical properties of passive and active stabilizers. Clin Orthop Relat Res 1996;(330):13-30. Crossref

3. Romeo AA, Cohen BS, Carreira DS. Traumatic anterior shoulder instability. Orthop Clin North Am 2001;32(3):399-409. Crossref

4. Hovelius L, Eriksson K, Fredin H, Hagberg G, Hussenius A, Lind $B$, et al. Recurrences after initial dislocation of the shoulder. Results of a prospective study of treatment. J Bone Joint Surg Am 1983;65(3):343-9. Crossref

5. Hovelius $L$. The natural history of primary anterior dislocation of the shoulder in the young. J Orthop Sci 1999;4(4):307-17. Crossref

6. Hovelius L, Olofsson A, Sandström B, Augustini BG, Krantz L, Fredin $\mathrm{H}$, et al. Nonoperative treatment of primary anterior shoulder dislocation in patients forty years of age and younger. A prospective twenty-five-year follow-up. J Bone Joint Surg Am 2008;90(5):945-52. Crossref

7. Greis PE, Scuderi MG, Mohr A, Bachus KN, Burks RT. Glenohumeral articular contact areas and pressures following labral and osseous injury to the anteroinferior quadrant of the glenoid. J Shoulder Elbow Surg 2002;11(5):442-51. Crossref

8. Freedman KB, Smith AP, Romeo AA, Cole BJ, Bach Jr BR. Open Bankart repair versus arthroscopic repair with transglenoid sutures or bioabsorbable tacks for Recurrent Anterior instability of the shoulder: a meta-analysis. Am J Sports Med 2004;32(6):1520-7. Crossref

9. Hubbell JD, Ahmad S, Bezenoff LS, Fond J, Pettrone FA. Comparison of shoulder stabilization using arthroscopic transglenoid sutures versus open capsulolabral repairs: a 5-year minimum follow-up. Am J Sports Med 2004;32(3):650-4. Crossref

10. el Akad AM, Winge S, Molinari M, Erikkson E. Arthroscopic Bankart procedures for anterior shoulder instability. A review of the literature. Knee Surg Sports Traumatol Arthrosc 1993;1(2):113-22. Crossref

11. Cole BJ, L'Insalata J, Irrgang J, Warner JJ. Comparison of arthroscopic and open anterior shoulder stabilization. A two to six-year follow-up study. J Bone Joint Surg Am 2000;82(8):1108-14. Crossref

12. Levy DM, Cole BJ, Bach Jr. BR. History of surgical intervention of anterior shoulder instability. J Shoulder Elbow Surg 2016;25(6):e139-50. Crossref

13. Balg F, Boileau P. The instability severity index score. A simple pre-operative score to select patients for arthroscopic or open shoulder stabilisation. J Bone Joint Surg Br 2007;89(11):14707. Crossref

14. Phadnis J, Arnold C, Ermorsy A, Flannery M. Utility of the Instability Severity Index Score in predicting failure after arthroscopic anterior stabilization of the shoulder. Am J Sports Med 2015;43(8):1983-8. Crossref 
15. Aboalata M, Seppel G, Juretzko J, Vogt S, Imhoff AB. Results of arthroscopic Bankart repair for anterior-inferior shoulder instability at 13-year follow-up. Am J Sports Med 2017;45(4):7827. Crossref

16. Di Giacomo G, de Vita A, Costantini A, de Gasperis N, Scarso P. Management of humeral head deficiencies and glenoid track. Curr Rev Musculoskelet Med 2014;7(1):6-11. Crossref

17. Locher J, Wilken F, Beitzel K, Buchmann s, Longo UG, Denaro $V$, et al. Hill-Sachs off-track lesions as risk factor for recurrence of instability after arthroscopic bankart repair. Arthroscopy 2016;32(10):1993-9. Crossref

18. Karlsson J, Magnusson L, Ejerhed L, Hultenheim I, Lundin O, Kartus J. Comparison of open and arthroscopic stabilization for recurrent shoulder dislocation in patients with a Bankart lesion. Am J Sports Med 2001;29(5):538-42. Crossref

19. Nho SJ, Frank RM, Van Thiel GS, Wang FC, Wang VM, Provencher MT, et al. A biomechanical analysis of anterior Bankart repair using suture anchors. Am J Sports Med 2010;38(7):1405-12. Crossref

20. Hagstrom LS, Marzo JM. Simple versus horizontal suture anchor repair of Bankart lesions: which better restores labral anatomy? Arthroscopy 2013;29(2):325-9. Crossref

21. Shibata H, Gotoh M, Mitsui Y, Kai Y, Nakamura H, Kanazawa T, et al. Risk factors for shoulder re-dislocation after arthroscopic Bankart repair. J Orthop Surg Res 2014;9:53. Crossref

22. Boileau P, Villalba M, Héry JY, Balg F, Ahrens P, Neyton L. Risk factors for recurrence of shoulder instability after arthroscopic Bankart repair. J Bone Joint Surg Am 2006;88(8):1755-63. Crossref

23. Brown L, Rothermel S, Joshi R, Dhawan A. Recurrent instability after arthroscopic Bankart reconstruction: a systematic review of surgical technical factors. Arthroscopy 2017;33(11):2081-92. Crossref

24. Hayashi K, Thabit G 3rd, Massa KL, Bogdanske JJ, Cooley AJ, Orwin JF, et al. The effect of thermal heating on the length and histologic properties of the glenohumeral joint capsule. Am J Sports Med 1997;25(1):107-12. Crossref

25. Hecht P, Hayashi K, Cooley AJ, Lu Y, Fanton GS, Thabit G 3rd, et al. The thermal effect of monopolar radiofrequency energy on the properties of joint capsule. An in vivo histologic study using a sheep model. Am J Sports Med 1998;26(6):808-14. Crossref

26. Chen S, Haen PS, Walton J, Murrell GA. The effects of thermal capsular shrinkage on the outcomes of arthroscopic stabilization for primary anterior shoulder instability. Am J Sports Med 2005;33(5):705-11. Crossref

27. McRae S, Leiter J, Subramanian K, Litchfield R, MacDonald P.Randomized controlled trial of arthroscopic electrothermal capsulorrhaphy with Bankart repair and isolated arthroscopic Bankart repair. Knee Surg Sports Traumatol Arthrosc 2016;24(2):414-21. Crossref

28. Sekiya JK. Arthroscopic labral repair and capsular shift of the glenohumeral joint: technical pearls for a multiple pleated plication through a single working portal. Arthroscopy 2005;21(6):766. Crossref
29. Sekiya JK, Willobee JA, Miller MD, Hickman AJ, Willobee A. Arthroscopic multi-pleated capsular plication compared with open inferior capsular shift for reduction of shoulder volume in a cadaveric model. Arthroscopy 2007;23(11):1145-51. Crossref

30. Latarjet M. Treatment of recurrent dislocation of the shoulder. Lyon Chir 1954;49(8):994-7.

31. Burkhart SS, De Beer JF, Barth JR, Cresswell T, Roberts C, Richards DP. Results of modified Latarjet reconstruction in patients with anteroinferior instability and significant bone loss. Arthroscopy 2007;23(10):1033-41. Crossref

32. Hovelius L, Sandström B, Sundgren K, Saebö M. One hundred eighteen Bristow-Latarjet repairs for recurrent anterior dislocation of the shoulder prospectively followed for fifteen years: study I-clinical results. J Shoulder Elb Surg 2004;13(5):509-16. Crossref

33. Miniaci A, Gish MW. Management of anterior glenohumeral instability associated with large Hill-Sachs defects. Tech Shoulder Elb Surg 2004;5(3):170-5. Crossref

34. Longo UG, Loppini M, Rizzello G, Ciuffreda M, Berton A, Maffulli N, et al. Remplissage, humeral osteochondral grafts, weber osteotomy, and shoulder arthroplasty for the management of humeral bone defects in shoulder instability: systematic review and quantitative synthesis of the literature. Arthroscopy 2014;30(12):1650-66. Crossref

35. DeFroda S, Bokshan S, Stern E, Sullivan K, Owens BD. Arthroscopic Bankart repair for the management of anterior shoulder instability: indications and outcomes. Curr Rev Musculoskelet Med 2017;10(4):442-51. Crossref

36. Virk MS, Manzo RL, Cote M, Ware JK, Mazzocca AD, Nissen CW, et al. Comparison of time to recurrence of instability after open and arthroscopic Bankart repair techniques. Orthop J Sports Med 2016;4(6):2325967116654114. Crossref

37. Chechik O, Maman E, Dolkart O, Khashan M, Shabtai L, Mozes G. Arthroscopic rotator interval closure in shoulder instability repair: a retrospective study. J Shoulder Elbow Surg 2010;19(7):1056-62. Crossref

38. Milano G, Grasso A, Santagada DA, Saccomanno MF, Deriu L, Fabbriciani C. Comparison between metal and biodegradable suture anchors in the arthroscopic treatment of traumatic anterior shoulder instability: a prospective randomized study. Knee Surg Sports Traumatol Arthrosc 2010;18(12):1785-91. Crossref

39. Tan CK, Guisasola I, Machani B, Kemp G, Sinopidis C, Brownson $P$, et al. Arthroscopic stabilization of the shoulder: a prospective randomized study of absorbable versus nonabsorbable suture anchors. Arthroscopy 2006;22(7):716-20. Crossref

40. Ahmed I, Ashton F, Robinson CM. Arthroscopic Bankart repair and capsular shift for recurrent anterior shoulder instability: functional outcomes and identification of risk factors for recurrence. J Bone Joint Surg Am 2012;94(14):1308-15. Crossref

41. Wang L, Liu Y, Su X, Liu S. a meta-analysis of arthroscopic versus open repair for treatment of Bankart lesions in the shoulder. Med Sci Monit 2015;21:3028-35. Crossref 
42. Haroun HK, Sobhy MH, Abdelrahman AA. Arthroscopic Bankart repair with remplissage versus Latarjet procedure for management of engaging Hill-Sachs lesions with subcritical glenoid bone loss in traumatic anterior shoulder instability: a systematic review and meta-analysis. J Shoulder Elbow Surg 2020;29(10):2163-74. Crossref

43. Donohue MA, Owens BD, Dickens JF. Return to play following anterior shoulder dislocation and stabilization surgery. Clin Sports Med 2016;35(4):545-61. Crossref
44. Memon M, Kay J, Cadet ER, Shahsavar S, Simunovic N, Ayeni OR. Return to sport following arthroscopic Bankart repair: a systematic review. J Shoulder Elbow Surg 2018;27(7):1342-7. Crossref 